\title{
Pré-natal do parceiro: uma análise a partir da perspectiva da gestante
}

\author{
Partner's prenatal: an analysis from the perspective of the pregnant \\ Prenatal de lo compañero: un análisis desde la perspectiva de la embarazada
}

Rosyanne da Silva e Silva ${ }^{1}$, Silvana Cordeiro de Oliveira ${ }^{1}$, Adriana Paiva Camargo Saraiva ${ }^{1 *}$.

\begin{abstract}
RESUMO
Objetivo: Analisar a adesão ao pré-natal do parceiro a partir da perspectiva das gestantes. Métodos: Estudo transversal descritivo, de abordagem quantitativa, aprovado por Comitê de Ética em Pesquisa, com 84 gestantes entre abril e outubro de 2019, nas Estratégias de Saúde da Família da zona urbana de um município do interior do Pará. Os dados foram analisados utilizando o software IBM SPSS Statistics. Resultados: O maior percentual se autodeclarou de cor parda (60; 71,4\%), união estável (36; 42,9\%), ensino médio $(54 ; 64,3 \%)$, com 0 a 1 filho $(67$; $79,8 \%$ ). Cerca de $70 \%$ desconheciam o pré-natal do parceiro, $22,6 \%$ foram informadas pelo enfermeiro, $33,3 \%$ dos parceiros acompanhavam as gestantes em suas consultas, $6 \%$ realizaram o pré-natale $87,3 \%$ gostariam que 0 parceiro fosse mais participativo. Quanto à não adesão ao programa, 45,6\% alegaram o trabalho do parceiro como principal motivo. Conclusão: A maioria das gestantes desconhecem o programa e alegam que não foram informadas pelos enfermeiros. Na perspectiva das gestantes, a maioria gostaria que o parceiro participasse, mas são poucos os homens que realizam o pré-natal, confirmando a hipótese da baixa adesão.
\end{abstract}

Palavras-chave: Cuidado pré-natal, Gestante, Saúde do homem.

\section{ABSTRACT}

Objective: To analyze the adherence to the partner's prenatal care from the perspective of pregnant women. Methods: Descriptive cross-sectional study, with a quantitative approach, approved by the Research Ethics Committee, with 84 pregnant women between April and October 2019, in Family Health Strategies in the urban area of a municipality of interior of Pará. The data were analyzed using IBM SPSS Statistics software. Results: The highest percentage declared themselves to be brown (60; 71.4\%), stable union (36; $42.9 \%)$, high school $(54,64.3 \%)$, with 0 to 1 child $(67 ; 79,8 \%)$. About $70 \%$ did not know the partner's prenatal care, $22.6 \%$ were informed by the nurse, $33.3 \%$ of the partners accompanied the pregnant women in their consultations, $6 \%$ performed the prenatal care and $87.3 \%$ would like the partner be more participatory. Regarding non-adherence to the program, $45.6 \%$ declared the partner's work as the main reason. Conclusion: Most pregnant women are unaware of the program and claim that they were not informed by the nurses. From the perspective of pregnant women, most would like their partner to participate, but few men do prenatal care, confirming the hypothesis of low adherence.

Keywords: Prenatal care, Pregnant women, Men's health.

\section{RESUMEN}

Objetivo: Analizar la adherencia del compañero a la atención prenatal desde la perspectiva de las mujeres embarazadas. Métodos: Estudio transversal descriptivo, con enfoque cuantitativo, aprobado por Comité de Ética en Investigación, con 84 mujeres embarazadas entre abril y octubre de 2019, en Estrategias de salud familiar en el área urbana de un municipio del interior de Pará. Los datos se analizaron utilizando el software IBM SPSS Statistics. Resultados: El porcentaje más alto se declaró marrón (60; 71.4\%), unión estable (36; 42.9\%), escuela secundaria $(54,64.3 \%)$, con 0 a 1 niño $(67 ; 79.8 \%)$. Acerca de $70 \%$ desconocía la atención prenatal de lo compañero, el 22,6\% fue informado por la enfermera, el $33,3 \%$ de los compañeros acompañó a las mujeres embarazadas en sus consultas, el $6 \%$ realizó la atención prenatal y al $87,3 \%$ le gustaría que lo compañero ser más participativo. En cuanto a la no adhesión al programa, el $45,6 \%$ afirmó que el trabajo de lo compañero era la razón principal. Conclusión: La mayoría de las mujeres embarazadas desconocen el programa y afirman que las enfermeras no les informaron. Desde la perspectiva de las mujeres, a la mayoría le gustaría que su compañero participara, pero pocos realizan atención prenatal, lo que confirma la hipótesis de baja adherencia.

Palabras clave: Atención prenatal, Mujeres embarazadas, Salud del hombre.

${ }^{1}$ Universidade do Estado do Pará (UEPA), Conceição do Araguaia - PA. *E-mail: adriana.saraiva@uepa.br SUBMETIDO EM: 6/2020

PUBLICADO EM: 12/2020 


\section{INTRODUÇÃO}

No Brasil, o assunto inerente a saúde reprodutiva do homem começou a ter repercussão a partir de 1996, onde foi regulado o parágrafo $7^{\circ}$ do artigo 226 da Constituição Federal, através da Lei ํㅡ 9.263, esta referese ao planejamento familiar, que se configura como direito de todo indivíduo, compreendendo uma série de ações que visa regular a fecundidade e prole da mulher, do homem e da família (BRASIL, 1996).

Todavia, o homem só teve sua saúde priorizada com a criação da Política Nacional de Atenção Integral à Saúde do Homem (PNAISH), instituída pela Portaria no 1.944 em agosto de 2009, que se refere a proteção, promoção de saúde e a prevenção de agravos, complementando a busca por melhores condições de saúde da população masculina (MOZZAQUATRO CO, ARPINI DM, 2017; BRASIL, 2009).

Desse modo, a partir de então o homem deveria ser incentivado a cuidar de sua saúde e procurar os serviços de atenção básica, com o intuito principal de promover ações de saúde com ênfase nas suas particularidades e no ambiente em que vive, possuindo deveres e direitos em relação ao planejamento reprodutivo, não apenas em uma perspectiva legal como ainda o direito da escolha de ser ou não pai e principalmente de participar da gravidez, do parto, do puerpério e da educação de seus filhos (BRASIL, 2009; MOZZAQUATRO CO, ARPINI DM, 2017).

Nesse sentido, o pré-natal do parceiro foi incluído dentro da PNAISH por volta do ano de 2012 como um projeto, que garantisse o autocuidado do homem e a execução de uma paternidade responsável, se transcrevendo como indispensável para assistência ao período gravídico-puerperal, e aos poucos se difunde nas Estratégias de Saúde da Família (ESF), expandindo o acesso do homem aos serviços de saúde, e firmando sua paternidade desde a descoberta da gravidez, o que gera vínculo entre as partes envolvidas, e uma série de impactos positivos na saúde materna e neonatal (BRASIL, 2009; HERRMANN A, et al., 2016).

A vivência do homem no pré-natal também transcreve uma nova visão a respeito do papel dele na sociedade e com sua família, pois mediante as orientações que lhes são transmitidas, a paternidade ganha um posicionamento de alguém que possui sentimentos, capaz de experimentar todas as alterações emocionais de sua parceira, o que gera vínculo, e o homem que outrora se via apenas como provedor, passa a atuar como protetor, pai, esposo e em especial, consegue desenvolver um convívio familiar sem qualificar as tarefas de mãe e pai, pois seus papéis se complementam, e ambos se responsabilizam pelo bem-estar do filho (BRAIDE ASG, 2018).

Nesse sentido, o pré-natal do parceiro possui algumas etapas e ações, a primeira delas é o acolhimento, em que será discutido com o casal a forma como o pai participará do pré-natal, parto e puerpério, enfatizando seus anseios relacionados a esses processos, planejando uma linha de cuidado considerando as individualidades do homem. A segunda etapa volta-se para a garantia da realização de exames, testes rápidos, vacinação, consulta odontológica e tratamento para Sífilis, em caso positivo (GOMES R, et al., 2016; HERRMANN A, et al., 2016).

De acordo com o Ministério da Saúde (2018) na caderneta da gestante possui um espaço para preencher os resultados dos exames que devem ser realizados pelo homem, sendo: tipagem sanguínea pelo sistema ABO e fator Rh, glicemia, teste Venereal Disease Research Laboratory (VDRL) para sífilis, teste rápido para o vírus da imunodeficiência humana (HIV) teste para hepatite $\mathrm{C}$ e teste Hepatitis $B$ Surface Antigen (HBsAg) para hepatite $\mathrm{B}$, hemograma, lipidograma, dosagem de colesterol de alta e baixa densidade, sendo o high densitity lipoprotein (HDL) e low density lipoprotein (LDL), colesterol total, o exame complementar eletroforese de hemoglobina. Quanto às vacinas o homem deve estar com o esquema completo ou completar as doses da Antitetânica, Hepatite B e Febre Amarela.

A terceira se relaciona com o acompanhamento e avaliação das consultas de pré-natal, em que o profissional estabelecerá um diálogo com o intuito de sanar dúvidas e realizar orientações que envolvam o relacionamento do homem com a parceira, a gestação e nascimento da criança. Deve ainda, orientar quanto ao acompanhamento do pai no parto e puerpério, respeitando sempre a vontade da mulher (GOMES R, et al., 2016; HERRMANN A, et al., 2016). 
Gomes R, et al. (2016) evidenciam que alguns estudos abordam o envolvimento do parceiro no pré-natal, expondo fatores que muitas vezes se apresentam como barreira para tal participação, sendo estes, em sua maioria, de caráter cultural, em que a mulher é responsável pelos filhos, que o homem não necessita frequentar as unidades de saúde, ou o não reconhecimento de sua importância durante a gestação, ou ainda de um certo preconceito quanto a sua participação no pré-natal, seja por parte dos profissionais, de sua parceira ou dele mesmo. Além disso, também relatam que o horário do trabalho pode ser um empecilho para realizar o pré-natal.

Nogueira JRDF e Ferreira M (2012) identificaram, de acordo com achados na literatura científica, que alguns fatores contribuem para o homem não realizar o pré-natal, dentre eles: a idade da parceira, conflitos conjugais, sentimentos de medo, insegurança e gravidez indesejada, se destacam como prejudiciais para a interação do homem no processo de pré-natal e o afasta do vínculo afetivo com sua parceira e filho.

Desse modo, apesar de diversos fatores desmotivarem o homem a aderir ao pré-natal do parceiro, algumas políticas públicas incentivam essa participação no pré-natal, parto e puerpério, como a Rede Cegonha que enfoca no planejamento reprodutivo e assistência humanizada à gestante e criança, sendo o homem importante nesse contexto; e a Lei Federal $n=11.108 / 05$, que dispõe a respeito do direito da gestante em ter um acompanhante de sua escolha, sendo na maioria das vezes seu parceiro o escolhido (HERRMANN A, et al., 2016).

Assim, de acordo com a literatura revisada, o pré-natal do parceiro se caracteriza como um programa de grande relevância para incluir o homem durante a gravidez, além de incentivá-lo a procurar os serviços de saúde, refletindo diretamente no vínculo entre o homem, a gestante e seu filho antes mesmo do nascimento, o que justifica realizar um estudo que investigue os motivos da não adesão do homem ao pré-natal do parceiro a partir da perspectiva das gestantes, já que são elas que mais frequentam a ESF.

Mediante a isso, a pesquisa teve como objetivo analisar a adesão ao pré-natal do parceiro a partir da perspectiva das gestantes, que realizavam o pré-natal nas ESF da zona urbana de um município do interior do Pará, bem como, caracterizar a amostra quanto aos aspectos sociodemográficos; verificar a adesão ao pré-natal do parceiro nas ESF do município; comparar a adesão entre as diferentes ESF e identificar os motivos que levam a não adesão ao pré-natal do parceiro.

\section{MÉTODOS}

Trata-se de um estudo transversal do tipo descritivo, com abordagem quantitativa, realizado em 9 (nove) ESF localizadas no perímetro urbano de um município do interior do Pará, região Sudeste do Estado, entre abril e outubro de 2019. A amostra foi constituída por 84 gestantes maiores de 18 anos, que já haviam realizado pelo menos uma consulta de pré-natal e que aceitaram assinar o Termo de Consentimento Livre e Esclarecido (TCLE). Foram excluídas as menores de 18 anos, que não aceitaram participar da pesquisa e as que não possuiam vínculo com o pai da criança ou não tinha algum parceiro.

Foi aplicado um questionário presencial, elaborado pelas autoras, contendo 16 perguntas, que analisou variáveis sociodemográficas: ESF, idade, estado civil, escolaridade, quantidade de filhos, cor da pele; e as variáveis específicas: quantidade de consultas realizadas na gestação atual, Idade Gestacional (IG), conhecimento da existência do pré-natal do parceiro, se o enfermeiro informou a respeito, quais motivos considera que o leva a não participar, se gostaria que seu parceiro participasse do pré-natal do parceiro e ainda, na perspectiva dela, quais pontos positivos e negativos dessa participação.

A pesquisa foi desenvolvida mediante parecer consubstanciado favorável número: 3.216.564, emitido pelo Comitê de Ética em Pesquisa do Araguaia (CEPAr), atendendo as exigências éticas definidas pela Resolução 466/2012. A participação das gestantes foi voluntária, sendo solicitado leitura e assinatura do TCLE previamente à aplicação do questionário.

Considerando amostras independentes, o teste da razão de verossimilhança do Qui-quadrado foi utilizado com nível de significância de $p$-valor $<0.05$. Os dados coletados foram tabulados por meio do processamento no sistema Microsoft Excel; bem como interpretados, processados e analisados por meio da estatística descritiva e inferencial. Para a análise estatística dos dados foi utilizado o software IBM Statistic Package for Social Sciences (SPSS) versão 24.0, em ambiente Windows 7. 


\section{RESULTADOS}

Cada ESF teve a participação de $10(11,9 \%)$ gestantes, exceto a ESF 5 que teve a participação de apenas $4(4,8 \%)$ gestantes. A maioria significativa das gestantes se autodeclararam pardas em relação a cor da pele (71,4\%), 54 (64,3\%) haviam concluido o ensino médio e $36(42,9 \%)$ viviam em união estável, sendo que 34 $(40,5 \%)$ possuiam apenas 1 filho enquanto $33(39,3 \%)$ não possuiam filhos no momento da apllicação do instrumento de coleta de dados (Tabela 1).

Tabela 1 - Distribuição das gestantes segundo a caracterização sociodemográfica.

\begin{tabular}{|c|c|c|c|}
\hline Caracterização & Frequência $(n=84)$ & Percentual (\%) & P-Valor(1) \\
\hline \multicolumn{4}{|l|}{ ESF } \\
\hline ESF 1 & 10 & $11,9 \%$ & \multirow{9}{*}{ - } \\
\hline ESF 2 & 10 & $11,9 \%$ & \\
\hline ESF 3 & 10 & $11,9 \%$ & \\
\hline ESF 4 & 10 & $11,9 \%$ & \\
\hline ESF 5 & 4 & $4,8 \%$ & \\
\hline ESF 6 & 10 & $11,9 \%$ & \\
\hline ESF 7 & 10 & $11,9 \%$ & \\
\hline ESF 8 & 10 & $11,9 \%$ & \\
\hline ESF 9 & 10 & $11,9 \%$ & \\
\hline \multicolumn{4}{|l|}{ Estado Civil } \\
\hline União Estável & 36 & $42,9 \%$ & \multirow{4}{*}{$X^{2}: 60,42$ / Valor-p: 0,000 } \\
\hline Casada & 30 & $35,7 \%$ & \\
\hline Solteira & 16 & $19,0 \%$ & \\
\hline Divorciada & 2 & $2,4 \%$ & \\
\hline \multicolumn{4}{|l|}{ Escolaridade } \\
\hline Ensino Médio & 54 & $64,3 \%$ & \multirow{3}{*}{$\mathrm{X}^{2}: 61,33$ / Valor-p: 0,000} \\
\hline $\begin{array}{c}\text { Ensino } \\
\text { Fundamental }\end{array}$ & 16 & $19,0 \%$ & \\
\hline Ensino Superior & 14 & $16,7 \%$ & \\
\hline \multicolumn{4}{|l|}{ Filhos } \\
\hline 0 & 33 & $39,3 \%$ & \multirow{5}{*}{$X^{2}: 32,021$ / Valor-p: 0,000 } \\
\hline 1 & 34 & $40,5 \%$ & \\
\hline 2 & 8 & $9,5 \%$ & \\
\hline 3 & 6 & $7,1 \%$ & \\
\hline 4 ou mais & 3 & $3,6 \%$ & \\
\hline \multicolumn{4}{|l|}{ Raça/Cor } \\
\hline Parda & 60 & $71,4 \%$ & \multirow{4}{*}{$X^{2}: 141,2$ / Valor-p: 0,000} \\
\hline Negra & 14 & $16,7 \%$ & \\
\hline Branca & 8 & $9,5 \%$ & \\
\hline Amarela & 2 & $2,4 \%$ & \\
\hline
\end{tabular}

Legenda: (1) Teste Qui-quadrado de Pearson ( $p$-valor $<0.05$ ).

*Valores Significativos; NS Valores Não Significativos.

$\mathrm{HO}$ : Não há tendência significativa entre as frequências observadas ( $p>0.05)$.

$\mathrm{H} 1$ : Há tendência significativa entre as frequências observadas $(p<0.05)$.

Fonte: Silva RS, et al., 2020.

A maioria das gestantes realizaram mais de 4 consultas (36; 42,9\%), 58 gestantes (69\%) desconheciam o pré-natal voltado ao parceiro, para $19(22,6 \%)$ gestantes o enfermeiro informou sobre este pré-natal. Nesse sentido, uma minoria dos parceiros acompanha as gestantes nas consultas $(28 ; 33,3 \%)$ e apenas $5(6 \%)$ dos parceiros realizavam o pré-natal, dentre estes, $3(60 \%)$ gestantes se sentem mais apoiadas pelo parceiro (Tabela 2).

O desconhecimento $(30 ; 38,0 \%)$ e o trabalho $(36 ; 45,6 \%)$ são os principais motivos que levam a não adesão ao pré-natal do parceiro sob a perspectiva das gestantes. Contudo, a maioria das gestantes investigadas gostariam que o parceiro participasse (69; 87,3\%) (Tabela 2). 
Tabela 2 - Distribuição das gestantes segundo a adesão ao pré-natal do parceiro.

\begin{tabular}{|c|c|c|c|}
\hline Adesão ao pré-natal do parceiro nas ESF & Frequência $(n=84)$ & Percentual (\%) & P-Valor(1) \\
\hline \multicolumn{4}{|l|}{ Consultas } \\
\hline 2 & 24 & $28,6 \%$ & \multirow{4}{*}{$\begin{array}{l}X^{2}: 20,3810 / \\
\text { Valor-p: } 0,000\end{array}$} \\
\hline 3 & 8 & $9,5 \%$ & \\
\hline 4 & 16 & $19,0 \%$ & \\
\hline Mais de 4 & 36 & $42,9 \%$ & \\
\hline \multicolumn{4}{|l|}{$\begin{array}{l}\text { Tem conhecimento sobre o pré-natal do } \\
\text { parceiro? }\end{array}$} \\
\hline Sim & 26 & $31,0 \%$ & \multirow{2}{*}{$\begin{array}{c}X^{2}: 88,0952 / \\
\text { Valor-p: } 0,000\end{array}$} \\
\hline Não & 58 & $69,0 \%$ & \\
\hline \multicolumn{4}{|l|}{ O enfermeiro informou? } \\
\hline Sim & 19 & $22,6 \%$ & \multirow{2}{*}{$\begin{array}{c}X^{2}: 25,1905 / \\
\text { Valor-p: } 0,000\end{array}$} \\
\hline Não & 65 & $77,4 \%$ & \\
\hline \multicolumn{4}{|l|}{ Parceiro acompanha nas consultas? } \\
\hline Sim & 28 & $33,3 \%$ & \multirow{2}{*}{$\begin{array}{c}X^{2}: 154,857 / \\
\text { Valor-p: } 0,000\end{array}$} \\
\hline Não & 56 & $66,7 \%$ & \\
\hline \multicolumn{4}{|l|}{ Ele realiza o pré-natal? } \\
\hline Sim & 5 & $6,0 \%$ & \multirow{2}{*}{$\begin{array}{c}X^{2}: 139,5 / \text { Valor } \\
\text { p: } 0,000\end{array}$} \\
\hline Não & 79 & $94,0 \%$ & \\
\hline \multicolumn{4}{|l|}{ Caso sim, quais pontos positivos? } \\
\hline Ele tem a chance de se consultar & 1 & $20,0 \%$ & \multirow{3}{*}{-} \\
\hline $\begin{array}{l}\text { Tem a experiência de participar de todos os } \\
\text { processos da gestação }\end{array}$ & 1 & $20,0 \%$ & \\
\hline Sinto mais apoio & 3 & $60,0 \%$ & \\
\hline \multicolumn{4}{|l|}{ Caso não, o que leva ele a não realizar? } \\
\hline Desconhecimento & 30 & $38,0 \%$ & \multirow{5}{*}{$\begin{array}{c}X^{2}: 165,44 / \\
\text { Valor-p: } 0,000\end{array}$} \\
\hline Falta de Interesse & 7 & $8,9 \%$ & \\
\hline Falta de Tempo & 5 & $6,3 \%$ & \\
\hline Trabalho & 36 & $45,6 \%$ & \\
\hline Outro & 1 & $1,3 \%$ & \\
\hline \multicolumn{4}{|l|}{$\begin{array}{l}\text { Caso não, você gostaria que ele } \\
\text { participasse? }\end{array}$} \\
\hline Sim & 69 & $87,3 \%$ & $\mathrm{X}^{2}: 121,23 /$ \\
\hline Não & 10 & $12,7 \%$ & Valor-p: 0,000 \\
\hline
\end{tabular}

Legenda: (1) Teste Qui-quadrado de Pearson (p-valor <0.05); *Valores Significativos; NS Valores Não Significativos; H0: Não há tendência significativa entre as frequências observadas ( $p>0.05) ; \mathrm{H} 1$ : Há tendência significativa entre as frequências observadas $(p<0.05)$.

Fonte: Silva RS, et al., 2020.

Verifica-se que apenas 5 (6\%) parceiros realizam o pré-natal sendo 1 (20\%) na ESF 3, 1 (20\%) na ESF 7, 1 (20\%) na ESF 8 e 2 (40\%) da ESF 9. Em 5 ESF não foi realizado o pré-natal do parceiro. Na ESF 5 foi encontrado o menor número de gestantes realizando o pré-natal durante o período da realização da pesquisa (Tabela 3).

Tabela 3 - Distribuição das ESF que realizam o pré-natal do parceiro segundo a perspectiva das gestantes.

\begin{tabular}{|c|c|c|c|c|}
\hline \multirow{3}{*}{ ESF } & \multicolumn{4}{|c|}{ Ele realiza o pré-natal? } \\
\hline & \multicolumn{2}{|c|}{ Sim } & \multicolumn{2}{|c|}{ Não } \\
\hline & $\mathbf{n}$ & $\%$ & $n$ & $\%$ \\
\hline ESF 1 & 0 & $0,0 \%$ & 10 & $12,7 \%$ \\
\hline ESF 2 & 0 & $0,0 \%$ & 10 & $12,7 \%$ \\
\hline ESF 3 & 1 & $20,0 \%$ & 9 & $11,4 \%$ \\
\hline ESF 4 & 0 & $0,0 \%$ & 10 & $12,7 \%$ \\
\hline ESF 5 & 0 & $0,0 \%$ & 4 & $5,1 \%$ \\
\hline ESF 6 & 0 & $0,0 \%$ & 10 & $12,7 \%$ \\
\hline ESF 7 & 1 & $20,0 \%$ & 9 & $11,4 \%$ \\
\hline ESF 8 & 1 & $20,0 \%$ & 9 & $11,4 \%$ \\
\hline ESF 9 & 2 & $40,0 \%$ & 8 & $10,1 \%$ \\
\hline
\end{tabular}

Legenda: (1) Teste Qui-quadrado de Pearson ( $p$-valor <0.05); *Valores Significativos; NS Valores Não Significativos; H0: Não há tendência significativa entre as frequências observadas ( $p>0.05) ; H 1$ : Há tendência significativa entre as frequências observadas $(p<0.05)$; $P$-Valor $=0.0231^{*}$.

Fonte: Silva RS, et al., 2020. 


\section{DISCUSSÃO}

Quanto a ESF, a Tabela 1 mostra que houve a participação de 10 gestantes em 8 (oito) ESF enquanto que na ESF número 5 houve participacipação de apenas 4 gestantes. De acordo com Esposti CDD, et al. (2015) a empatia com a equipe de saúde pode explicar a baixa adesão, mas outro fator mais provável para o caso do presente estudo, é a característica geográfica, pois a unidade é localizada em um bairro com território pequeno e ainda pelo fato de existir outras unidades próximas, o que favorece para tal fator (ROCHA IMS, et al., 2017).

No tocante ao perfil sociodemográfico, a maioria declarou viver em união estável, resultado que coincide com dados do Instituto Brasileiro de Geografia e Estatística (IBGE) (2010). Cardoso VEPS, et al.(2018) também observaram predomínio das gestantes com ensino médio completo, corroborando com os resultados do presente estudo. Em relação à quantidade de filhos, a maior parte $(40,5 \%)$ declarou possuir apenas 1 filho. De acordo com a Gerência de Informação e Análise de Situação em Saúde (GIASS) (2015) a taxa de fecundidade das mulheres na região norte do Brasil era de 1,70, no ano de 2015. Quanto à cor da pele, a maioria se autodeclarou parda $(71,4 \%)$, concordando com o que mostra o último censo do IBGE, no qual $69,9 \%$ dos paraenses se autodeclaram pardos (IBGE, 2010).

No que se refere à distribuição das gestantes participantes da pesquisa de acordo com o número de consultas de pré-natal, a maioria (36; $42,9 \%)$ havia realizado mais de quatro consultas, possivelmente pelo fato de que, um dos critérios de inclusão da pesquisa foram gestantes que já haviam realizado pelo menos uma consulta.

Ao avaliar o conhecimento das gestantes sobre a existênciado pré-natal do parceiro, $69,0 \%$ responderam que não conheciam. De acordo com Ministério da Saúde (2012) a presença do pai no pré-natal deve ser incentivada durante as consultas, pois é necessário garantir seu direito de ser informado e poder realizar o pré-natal do parceiro, que inclui consultas, exames e a troca de informações sobre a gestação, parto e puerpério.

Cardoso VEPS, et al. (2018) observaram que nas unidades de saúde estudadas, nenhuma possuía informativos sobre o pré-natal do parceiro ou incentivava as gestantes a trazerem seus parceiros para realização do pré-natal. Os autores enfatizam que o setor de saúde possui o dever de estimular essa participação, capacitando a gestante, ajustando horários e garantindo o apoio no desenvolvimento do prénatal do parceiro. Jardim MJA, et al. (2019), demonstraram que as gestantes recebem muitas informações sobre a questão biológica da gestação, todavia possuem informações limitadas, especialmente quanto aos seus direitos.

Quanto ao papel do enfermeiro no sentido de informar as gestantes sobre o pré-natal do parceiro, cerca de $77,4 \%$ não informou. Sendo assim, algumas hipóteses surgem para tentar explicar esse resultado, como por exemplo: a rotina de trabalho, os vários programas que precisam ser realizados, além da consulta de prénatal da gestante completa, que demanda muitas vezes boa parte do tempo do profissional, contando ainda com a estrutura do município, que pode não dispor de recursos para fazer valer esse programa.

Concomitante a esses fatores, ainda pode-se observar a questão cultural, pois, como citado por Cortez MB et al. (2016), muitos dos profissionais de saúde possuem certas dificuldades no que tange à saúde do homem, principalmente quando o assunto é voltado para a paternidade, o que contribui para a exclusão do pai nessa fase. Estes autores cogitaram a hipótese de que essa atitude pode estar relacionada à formação acadêmica dos enfermeiros anterior à Política Nacional de Atenção Integral à Saúde do Homem (PNAISH) instituída em 2009, e desta forma, possuem maior dificuldade em lidar com a assistência voltada para o parceiro. Contudo, deveriam evoluir nesse sentido, por atuarem na área dinâmica, técnica e científica da saúde, que oportuniza capacitações sobre as atualidades voltadas para a saúde.

Assim, observa-se que os cuidados durante a gestação se voltam, na maioria das vezes, para a mãe, fazendo com que o pai raramente participe desse processo, interferindo negativamente no envolvimento do homem com o bebê e sua companheira, afastando ainda mais o sentimento de pai antes do nascimento. Para Cavalcante TRL e Holanda VR (2019) os enfermeiros possuem um papel decisivo e devem ser os principais motivadores da inserção do homem no pré-natal, com objetivo de beneficiar a tríade mãe-pai-filho. 
Quanto à participação do pai nas consultas de pré-natal, obteve-se 33,3\%, as demais gestantes não eram acompanhadas por seus parceiros, o que pode interferir diretamente na adesão desses ao pré-natal. Holanda SM, et al. (2018) destacam a importância de o parceiro participar das consultas de pré-natal, tendo em vista que é nesse período que o mesmo é orientado quanto aos cuidados durante a gestação e ainda no pós-parto com sua companheira e seu filho. Rêgo RM, et al.(2016) evidenciam que o pai pode contribuir positivamente até mesmo para que seu filho receba amamentação exclusiva até os seis meses de vida, para que isso ocorra é essencial que esse seja incluso em todos os processos da gravidez até ao nascimento, refletindo assim no seu envolvimento com sua família.

No que tange à realização do pré-natal do parceiro, apenas 5 (cinco) das 84 gestantes $(6,0 \%)$ confirmaram que seus companheiros realizavam, destas, $3(60 \%)$ afirmaram que um dos pontos positivos é que se sentia mais apoiada por seu parceiro. Fiterman H e Moreira LVC (2018) observaram que durante o pré-natal a maioria dos homens ainda não se sente pai. O sentimento da paternidade antes do nascimento e envolvimento do homem na gestação é algo novo, que está em transformação na medida que os papéis do homem e da mulher vem rompendo antigos paradigmas e modificando o perfil das famílias, pois na atualidade a responsabilidade de provedor não necessariamente é exclusiva do homem.

Holanda SM, et al.(2018) ressaltam que a satisfação das gestantes durante o trabalho de parto, parto e puerpério foi maior quando o parceiro participou do pré-natal. Almeida MVS (2016) aborda que o envolvimento do pai na gestação é crucial para o desenvolvimento de apoio físico, emocional e social.

Em relação a não realização do pré-natal do parceiro, a maioria das gestantes responderam que seus parceiros não aderiram $(79 ; 94 \%)$, quando questionadas da possível razão que leva a baixa adesão ao prénatal do parceiro, $45,6 \%$ disseram que seus companheiros trabalhavam, o que remete a ideia do pai como provedor financeiro durante a gestação, Rêgo RM, et al. (2016) enfatizam que o conceito de pai, ao longo dos anos foi vinculado ao de sustentar financeiramente sua família. Trindade Z, et al. (2019) expressam que embora exista essa visão de paternidade, pôde identificar que o homem, está sendo gradativamente valorizado como alguém que está mais próximo e ativo no cuidado à sua família, e que o momento atual reflete uma mudança de conceitos e de possibilidades.

Outra justificativa da não adesão ao pré-natal foi a de que os parceiros não conheciam a respeito, isso se deve ao fato já citado, em que os profissionais de saúde, em sua maioria, centralizam sua assistência à gestante, esquecendo-se muitas vezes de incluir o homem nesse processo, quase sempre devido ao excesso de trabalho a que é submetido. Ainda $8,9 \%$ dos parceiros não tiveram interesse em participar da gestação, 6,3\% não tinham tempo de comparecer a ESF e 1,3\% respondeu ter outros motivos, enfatizando ainda mais que o homem por vezes, não ver a realização do pré-natal do parceiro como um direito, nem mesmo sabem de sua importância para saúde da gestante e do bebê.

Ferreira IS, et al. (2016) mencionam que o envolvimento do homem durante a gestação auxilia a gestante a comparecer nas consultas de pré-natal, a compreender melhor os processos inerentes a gestação, a sentirse mais segura e confiante, facilitando o cuidado e atenção à mulher. Além disso, quando o pai se envolve no pré-natal, a qualidade da assistência paterna e a responsabilidade do cuidado com o filho são melhores.

Na perspectiva das gestantes, $87,3 \%$ gostariam que o parceiro fosse mais participativo no pré-natal. Caldeira LA, et al. (2017) observam que as gestantes consideram o apoio do parceiro como algo positivo, em relação ao vínculo dela com seu filho, a aceitação da gravidez e os cuidados com sua saúde, quando o homem participa desse processo a mulher se sente estimulada a cuidar de si, pois nesse momento ela necessita de apoio, afeto e ações que Ihes ofereça segurança, para que possa lidar com todos os anseios inerentes a gestação.

Em contrapartida ao envolvimento do pai na gestação, das gestantes entrevistadas, 12,7\% não gostariam que o homem fosse mais participativo no pré-natal, possivelmente por não julgar importante o envolvimento do pai desde a gestação. Cardoso VEPS, et al. (2018) observaram que algumas mulheres preferem que seus parceiros não as acompanhe durante as consultas, pois consideram que o pré-natal é algo destinado à mulher e que não há necessidade de o homem interferir nesse processo, ou até mesmo no relacionamento dela com o profissional de saúde, que de acordo com uma delas, precisaria de privacidade. 
Das nove ESF onde ocorreu a pesquisa, apenas a ESF $3(1 ; 20 \%), 7(1 ; 20 \%), 8(1 ; 20 \%)$ e $9(2 ; 40 \%)$ foi identificada a realização do pré-natal do parceiro. A baixa adesão por parte das estratégias, provavelmente seja pelo fato de o município ainda não ter adicionado esse programa como rotina do pré-natal ou não dispõe de estrutura para efetivação do mesmo. Cavalcante TRL e Holanda VR (2019) retratam que o envolvimento do pai na gestação precisa ser um processo facilitado pelos serviços de saúde, para que possa se sentir acolhido e motivado a exercer a paternidade antes do nascimento.

Desse modo, percebe-se que há baixa adesão ao pré-natal do parceiro, justificado principalmente pelo fato do homem não poder comparecer às consultas por coincidir com seu horário de trabalho, além disso, as gestantes quase sempre, não são informadas a respeito do programa, o que dificulta ainda mais a inserção do homem nesse processo. Assim, observa-se que são diversos os fatores que contribuem para que o homem não participe ativamente do pré-natal, tendo em vista que depende de uma interação entre os serviços de saúde, profissionais de saúde, gestante e o homem.

\section{CONCLUSÃO}

De acordo com os dados obtidos é possível concluir que as gestantes participantes do estudo, predominantemente se encontram em união estável, possuem ensino médio completo, tem até dois filhos e se autodeclararam pardas. Quanto ao pré-natal do parceiro a maioria das gestantes desconhecem o programa e afirmam que os enfermeiros não as informaram a respeito. Na perspectiva das gestantes são poucos os homens que realizam o pré-natal, confirmando a hipótese do estudo. Quase a totalidade das gestantes gostariam de ter o parceiro participando do pré-natal, para que seja cuidado e orientado a exercer a paternidade desde a gestação, além de se sentirem mais apoiadas com a presença do mesmo.

\section{REFERÊNCIAS}

1. ALMEIDA MVS. A participação do pai no cuidado pré-natal de enfermagem: um olhar a luz da teoria de Madeleine Leininger. Rio de Janeiro, 2016. Tese (Doutorado em Enfermagem) - Escola de Enfermagem Anna Nery, Universidade Federal do Rio de Janeiro, Rio de Janeiro, 2016.

2. 2, BRAIDE ASG, et al. Sou homem e pai sim! (Re)construindo a identidade masculina a partir da participação no parto. Revista Panamericana de Salud Pública, 2018; 42(190):1-7.

3. BRASIL. Lei no 9.263, de 12 de Janeiro de 1996. Regula o $\S 7^{\circ}$ o do art. 226 da Constituição Federal, que trata do planejamento familiar, estabelece penalidades e dá outras providências. Brasília, 12 de Janeiro de 1996.

4. BRASIL. Ministério da Saúde. Secretaria de Atenção à Saúde. Departamento de Ações Programáticas e Estratégicas. Política Nacional de Atenção Integral à Saúde do Homem: princípios e diretrizes - Brasília: Ministério da Saúde, 2009 ; 92 p.: il. - (Série B. Textos Básicos de Saúde).

5. BRASIL. Ministério da Saúde. Secretaria de Atenção à Saúde. Departamento de Atenção ao pré-natal de baixo risco. Brasília: Editora do Ministério da Saúde, 2012; 318 p.: il. - (Série A. Normas e Manuais Técnicos) (Cadernos de Atenção Básica, no 32).

6. BRASIL. Ministério da Saúde. Caderneta da Gestante. 4aㅡ Edição. Brasília- DF. 2018.

7. CALDEIRA LA, et al. A visão das gestantes acerca da participação do homem no processo gestacional. Revista de Enfermagem do Centro-Oeste Mineiro, 2017; 7(e1417):1-10.

8. CARDOSO VEPS, et al. Participação do Parceiro na Rotina Pré-Natal Sob a Perspectiva da Mulher Gestante. Journal of Research: Fundamental Care Online, 2018; 10(3):856-862.

9. CAVALCANTE TRL, HOLANDA VR. Participação paterna no ciclo gravídico-puerperal e seus efeitos sobre a saúde da mulher. Enfermagem em Foco,2019; 10(1)93-98.

10. CORTEZ MB, et al. Profissionais de saúde e o (não) atendimento ao homem-pai: análise Em representações sociais. Psicologia em Estudo, Maringá, 2016; 21(1):53-63.

11. ESPOSTI CDD, et al. Travassos C. Representações sociais sobre o acesso e o cuidado pré - natal no Sistema Único de Saúde da Região Metropolitana da Grande Vitória, Espírito Santo. Saúde e Sociedade, 2015; 24(3):765-79.

12. FERREIRA IS, et al. Percepções de gestantes acerca da atuação dos parceiros nas consultas de pré-natal. Revista Rene, 2016;17(3)318-23.

13. FITERMAN H, MOREIRA LVC. O pai na gestação, no parto e aos trêsmeses de vida do primeiro filho. Polis, Revista Latinoamericana, 2018; 17(50):47-68.

14. GIASS. Gerência de Informação e Análise de Situação em Saúde. Relatório Epidemiológico sobre Natalidade - Região de Saúde Norte 2015, Distrito Federal, 2015.

15. GOMES R, et al. Linhas de cuidados masculinos voltados para a saúde sexual, a reprodução e a paternidade. Ciência \& Saúde Coletiva, 2016; 21(5):545-552.

16. HERRMANN A, et al. Guia do Pré-natal do parceiro para profissionais de Saúde. Rio de Janeiro: Ministério da Saúde. 2016.

17. HOLANDA SM, et al. Influência da participação do companheiro no pré-natal: satisfação de primíparas quanto ao apoio no parto. Texto Contexto Enfermagem, 2018;27(2):1- 10.

18. IBGE. Instituto Brasileiro de Geografia Estatística. Conceição do Araguaia. 2010.

19. JARDIM MJA, et al. Contribuições do Enfermeiro no Pré-Natal para a Conquista do Empoderamento da Gestante. Journal of Research: Fundamental Care Online, 2019;11(2):432-440

20. MOZZAQUATRO CO, ARPINI DM. Planejamento Familiar e papéis Parentais: o Tradicional, a Mudança e os Novos Desafios. Psicologia: Ciência e Profissão, 2017; 37(4):923-938.

21. NOGUEIRA JRDF, FERREIRA M. O envolvimento do pai na gravidez/parto e a ligação emocional com o bebé. Revista de Enfermagem Referência, 2012; 3(8):57-66.

22. REGO RM, et al. Paternidade e amamentação: mediação da enfermeira. Acta Paulista de Enfermagem, 2016; 29(4)374-80.

23. ROCHA IMS, et al. Fatores que influenciam a não adesão ao programa de pré-natal. Revista Recien, $2017 ; 7(21): 21-29$.

24. TRINDADE Z, et al. Pais de primeira viagem: demanda por apoioe visibilidade. Saúde e Sociedade, $2019 ; 28(1): 250-261$. 